\title{
Peranan Maidam Dalam Pengurusan Saudara Baru Melalui Pendekatan Dialog Kehidupan
}

\author{
The Role of MAIDAM in Managing Muslim Reverts Through Dialogue of Life \\ Aproaching
}

\begin{abstract}
Azarudin Awang (Pengarang Penghubung)
Academy Contemporary of Islamic Study, University Technology of Mara, Terengganu. Tel : +60-196622986 Email: azaru154@tganu.uitm.edu.my
\end{abstract}

\author{
Khadijah Mohd Hambali \\ Akidah and Islamic Thought Department, Academy of Islamic Study, University of Malaya, \\ Kuala Lumpur \\ Tel: +60-192708009 Email: ijamh@um.edu.my
}

\begin{abstract}
Abstrak
Majlis Agama Islam Dan Adat Melayu Terengganu (MAIDAM) bertanggungjawab sepenuhnya terhadap pengurusan Saudara Baru. Termasuk disini pengurusan yang melibatkan akal, emosi dan perasaan bagi komuniti Saudara Baru yang mempengaruhi hubungan dengan ahli keluarga bukan Muslim. Justeru, pembangunan intelektual melalui pengurusan dialog kehidupan bertujuan membetulkan salah faham, membaiki keadaan dan memupuk hubungan yang harmoni antara dua pihak yang terlibat. Kajian ini adalah bertujuan melihat peranan yang dilakukan oleh pihak MAIDAM dalam menguruskan permasalahan tersebut melalui pendekatan dialog kehidupan. Justeru, kajian ini menggunakan kaedah kuantitatif bagi melihat persepsi Saudara Baru terhadap pendekatan dialog kehidupan dalam menguruskan salah faham beragama antara komuniti Saudara Baru dengan ahli keluarga. Dengan menggunakan SPSS 20, data-data dianalisa menggunakan kaedah min dan peratus. Hasil kajian menunjukkan persepsi Saudara Baru terhadap peranan MAIDAM dalam membina hubungan antara masyarakat Islam dan bukan Islam berdasarkan pendekatan dialog kehidupan berada pada tahap yang sederhana. Biarpun begitu, hasil dapatan memperlihatkan majoriti responden berpandangan bahawa pelaksanaan dialog kehidupan dapat menjana hubungan yang harmonis dengan keluarga bukan Muslim.
\end{abstract}

Katakunci: Peranan; MAIDAM; Saudara Baru; Dialog Kehidupan

\begin{abstract}
Majlis Agama Islam and Malay Customs Terengganu (MAIDAM ) is fully responsible for the management of New Muslims. Mind, emotions and feelings management amongs New Muslims have affected relations with nonMuslim family. Thus, intellectual development through the dialogue of life is meant to correct any misconceptions, handle any situation and promote a harmonious relationship between the two parties. This study was designed to determine the MAIDAM 's role in managing the problems through implementing a dialogue of life. The quantitative methods used to determine the perception of Muslim reverts through dialogue of life in managing religious misunderstanding between Muslim reverts community with family members. Using SPSS 20, the data were analyzed using mean and percentage. The results showed that the perception of Muslim reverts to the role of MAIDAM in building the relations between Muslims and non-Muslim which based on a dialogue of life is at the medium level. Even so, the findings showed the majority of respondents believe that the implementation of the dialogue of life can generate good relations with nonMuslim families.
\end{abstract}


Keywords : Role; MAIDAM; Muslim reverts; Dialogue of Life

\section{Sejarah dan Perkembangan Majlis Agama Islam dan Adat Melayu (Maidam) Terengganu}

Peranan Majlis Agama Islam Dan Adat Melayu (MAIDAM) adalah sebagai entiti yang menguruskan pembangunan agama Islam di negeri Terengganu secara dominan apabila undang-undang Islam bil.1 1949 mula diwartakan pada 16 Februari pada tahun yang sama. Dalam rekod tersebut dinyatakan bahawa MAIDAM berfungsi sebagai penasihat kepada Sultan dalam perihal undang-undang Islam dan adat istiadat Melayu. Dengan yang demikian, Undang-Undang tersebut dinamakan sebagai Undang-Undang Majlis Agama Islam dan Adat Istiadat Melayu 1949. Pada peringkat awal, keahlian MAIDAM terdiri daripada 3 orang ahli rasmi yakni di bawah kekuasaan kerajaan Negeri dan tidak kurang daripada 5 orang ahli yang tidak rasmi. Selanjutnya, Undang-Undang tersebut dipinda 6 tahun berikutnya dan dinamakan Undang-Undang Pentadbiran Hukum Syarak Tahun 1955 $(1375 \mathrm{H})$. Hal yang tercatat di bahagian III di bawah fasa 6 hingga 21 telah menghapuskan perkataan 'istiadat' dan menampakkan peranan badan ini yang lebih jelas dan terarah (Abdul Halim 2012).

Bermula dari tarikh 1 Julai 1958, senarai keahlian Majlis ini mula diwartakan dari semasa ke semasa hingga sekarang. Pada peringkat ini, seorang Pesuruhjaya Hal Ehwal Agama telah dilantik dan bertindak sebagai Yang Di Pertua Majlis. Pada 26 Mac 1987 Kerajaan negeri Terengganu mewartakan Enakmen Pentadbiran Hal Ehwal Agama Islam 1986. Menurut catatan enakmen ini, seorang Setiausaha dilantik bagi memperkasakan pengurusan Jabatan Hal Ehwal Agama Terengganu (JHEAT). Selanjutnya, sekali lagi enakmen ini dipinda pada tahun 1992 yang memberi lebih kuasa kepada setiausaha yang sebelumnya bagi JHEAT kepada lantikan bagi Majlis. Manakala pada tarikh 10 April 1996, enakmen yang diluluskan memberi lantikan YAB Menteri Besar sebagai Yang DiPertua Majlis dan Pesuruhjaya Hal Ehwal Agama sebagai Setiausaha Majlis secara automatik (Abdul Halim 2012).

Struktur pentadbiran Majlis ini dipinda semula pada 30 Jun 1998, Setiausaha Majlis bertindak sebagai Ketua Pegawai Eksekutif yang melaksanakan segala perihal yang berkaitan dengan Majlis. Begitu juga perkataan 'Jabatan' dan 'Pesuruhjaya' dalam enakmen diubah kepada Majlis. Selanjutnya pada 22 November 2001, kerajaan negeri Terengganu telah meluluskan Enakmen Pentadbiran Hal Ehwal Agama Islam (Terengganu) 1422H/2001M dan enakmen ini berkuatkuasa pada 1 Ogos 2002. Begitu juga pindaan-pindaan yang dilakukan pada tahun 2003 dan 2008. Melalui pindaan ini, Menteri Besar tidak lagi dilantik sebagai Yang Dipertua Majlis. Pindaan yang seterusnya dilakukan pada 25 April 2012 telah meluluskan Enakmen Pentadbiran Hal Ehwal Agama Islam (Terengganu) kepada dua puluh satu seksyen (Abdul Halim 2012).

Sistem pengurusan hal ehwal agama Islam di negeri Terengganu mengalami proses perkembangan perubahan serentak dengan perkembangan dan pertambahan masyarakat Muslim. Peranan Majlis Agama Islam dan Adat Melayu (MAIDAM) dalam menguruskan hal ehwal agama Islam di negeri ini sekali gus membawa perubahan terhadap pengamalan dan penghayatan beragama melalui sistem yang disesuaikan mengikut perkembangan yang baharu. Hakikat ini semestinya menjadi pengaruh yang penting dalam kehidupan masyarakat Muslim seluruhnya dalam apa bidang sekalipun termasuk dalam aspek pembangunan sosio ekonomi, pendidikan, pemikiran dan politik.

Majlis Agama Islam dan Adat Melayu Negeri Terengganu (MAIDAM) merupakan satusatunya badan kerajaan yang berfungsi untuk memastikan pengurusan dan perjalanan hal ehwal Islam di negeri ini pada landasan yang betul termasuk dalam perihal Saudara Baru. 
Di bawah badan induk tersebut, Jawatankuasa Kegiatan Hal Ehwal Islam dan Jawatankuasa Temu duga Pendakwah merupakan dua badan kecil yang mengendalikan urusan-urusan yang berkait Saudara Baru di negeri Terengganu. Jawatankuasa Kegiatan Hal Ehwal Islam berperanan merancang dan mencadangkan program-program yang sesuai untuk dilaksanakan bagi memajukan pentadbiran hal ehwal agama Islam dari aspek dakwah, pendidikan, penyelidikan, pembangunan rohaniah dan akhlak serta pembinaan insan. Manakala Jawatankuasa Temu duga Pendakwah memilih para pendakwah bagi menyebarkan agama Islam dan memberi latihan kepada golongan Saudara Baru. Pengurusan terhadap Saudara Baru di negeri Terengganu diletakkan di bawah pengelolaan Pusat Latihan Saudara Baru di Kompleks Darul Hidayah, MAIDAM yang terletak di Jalan Sultan Omar, Kuala Terengganu (Abdul Halim, 2012).

Jumlah keseluruhan Saudara Baru Negeri Terengganu dari tempoh 1990 hingga 2011 berdasarkan data dari Pejabat Agama Negeri (2012) adalah seramai 2043. Pengislaman paling ramai adalah terdiri dari komuniti Cina iaitu seramai 523 orang. Yang nyata ialah pengislaman banyak berlaku di daerah Kuala Terengganu iaitu melibatkan 36.36\% daripada jumlah keseluruhan pemelukan agama. Menurut Abdul Halim (2012), ini amat berkait dengan faktor Kuala Terengganu sebagai pusat pentadbiran negeri, pusat keilmuan dan pusat pelancongan utama di negeri ini. Justeru, ianya menjadi justifikasi utama mengapa Kuala Terengganu mencatatkan kadar pengislaman yang cukup tinggi berbanding daerah-daerah lain.

\section{Konsep Dialog Kehidupan}

Dialog dalam pengertian yang luas adalah satu perbincangan 'a discourse' (dalam bahasa Arab dinyatakan sebagai al-hiwār dan al-muhāwarah) yang dilahirkan melalui proses pertuturan atau perundingan antara dua pihak (Forward 2001, Ibnu Manzur 2001). Dialog kehidupan adalah sebahagian daripada dialog antara agama. Dialog ini merupakan satu medium interaksi yang didasarkan kepada nilai-nilai spiritual dan perkongsian hidup seharian bagi memberi kefahaman yang unggul terhadap perbezaan yang wujud dalam agama dan budaya. Berdasarkan matlamat ini, setiap peserta yang terlibat bertindak, berfikir dan menjalankan kehidupan tanpa prasangka yang buruk (Fitzgerald, 2005). Justeru, dialog kehidupan berbeza daripada dialog antara agama yang lain. Dialog antara agama yang lain seperti dialog teologi, dialog pengalaman iman dan dialog tindakan bersama merujuk kepada sebarang interaksi antara dua agama yang dilakukan secara formal, berlaku dalam kalangan pemimpin agama dan membincangkan isu-isu tertentu dalam agama. Ia biasanya dimanifestasikan di tempat yang khusus dan isunya bersifat lebih spesifik. Misalnya ia membincangkan konsep ketuhanan dalam dua agama atau perkongsian tentang pelaksanaan amalan tertentu dalam agama. (Rahimin et al. 2011). Biarpun begitu, konsep dialog kehidupan adalah lebih menyeluruh. Ia digunakan sebagai wahana yang berupa interaksi atau bukan interaksi yang unggul bagi membolehkan perkongsian hidup yang aman dan sejahtera dapat dicapai. Sehubungan itu, Tyaganda (2011) berpendapat dialog ini merupakan satu elemen interaksi tanpa bercakap (non-verbal) yang berkesan dalam memberi kefahaman terhadap perbezaan nilai yang wujud dalam sesebuah masyarakat yang berbeza agama. Dengan demikian, dialog kehidupan melibatkan semua anggota masyarakat dan tidak terikat pada masa dan tempat yang tertentu. Pendek kata, dialog kehidupan boleh berlaku di mana-mana sahaja sama ada di pejabat, di sekolah, di hospital, di dalam kenderaan awam dan sebagainya (Suraya \& Khadijah, 2010). Ini bermakna setiap manusia yang terlibat dalam dialog kehidupan yakni mengikuti amalan agama dan budaya masyarakat lain mampu mengungkap persoalan terhadap budaya hidup yang beraneka. Untuk itu, Volker (2004) menyatakan sebagaimana berikut: 
"The people experience the rites and festivals of the various religion when they are their family or neighbours, and sometimes take part themselves. Even in urban situations, such ecperiences are possible. This religious living-together does not neccesarily demand detailed knowledge of the principles of the other religions in question".

Setiap anggota masyarakat mempunyai kepercayaan dan keluhuran adat resam yang diwarisi. Oleh itu, masalah perbezaan kepercayaan, masalah hukum-hakam, hubungan dengan keluarga yang bukan Muslim dan pelaksanaan budaya asal dianggap isu-isu yang sering melatari antara hubungan Muslim baru dengan ahli keluarga bukan Muslim. Akibat penghijrahan agama, terutama sekali kepada agama Islam, soal hubungan antara agama telah menjadi kompleks dan rumit. Sehubungan dengan ini, Rahimin et al. (2011) menyatakan persoalan itu lebih tertumpu kepada 'perbezaan agama' itu sendiri dan antaranya kegagalan pemahaman dan pentafsiran ahli keluarga yang bukan Islam terhadap perkara-perkara yang berhubung kait terhadap dasar-dasar agama dab amalan Islam. Justeru, hubungan antara agama di Malaysia kadangkalanya berhadapan dengan dilema yang sangat besar khususnya apabila isu-isu tersebut berkesudahan dengan konflik. Misalnya penukaran agama Islam yang akhirnya terpaksa melalui proses perundangan seperti kes perebutan jenazah Moorthy, Rayapan dan Nyonya Tahir. Rasa tidak puas hati terhadap keputusan yang diisytiharkan oleh Mahkamah Syariah menyebabkan pihak keluarga bukan Muslim selanjutnya membuat notis rayuan di mahkamah Sivil (Mohamed Azam, 2006). Senario keparahan hubungan antara agama secara nyata juga ditonjolkan dalam aktiviti perkauman jalanan seperti peristiwa pelontaran anggota babi di masjid, perarakan kepala lembu serta pembakaran gereja dan surau amat menggerunkan masyarakat (Dawi, 2010). Adalah dengan tujuan dan keperluan menyuburkan perpaduan, maka pihak-pihak yang berkaitan harus mengarahkan pelbagai usaha menuju kepada titik pertemuan, persefahaman dan persetujuan agar semua masyarakat hidup bermuafakat. Lantaran itu, penegasan soal pengurusan Saudara Baru melalui pendekatan dialog kehidupan dengan menonjolkan aktiviti lazim yang berlaku secara spontan dalam komuniti tersebut, pemahaman terhadap budaya orang lain pastinya akan meningkatkan skala hubungan toleransi dalam kehidupan beragama.

\section{Peranan Maidam Dalam Mengurus Perbezaan Pandangan Melalui Pendekatan Dialog Kehidupan}

Kesedaran, kefahaman dan; penglibatan Saudara Baru dan ahli keluarga bukan Muslim pada peringkat akar umbi menjadi kian perlu bagi mencapai pemupukan hubungan antara agama. Strategi pengurusan MAIDAM terhadap kebajikan Saudara Baru ditingkatkan melalui pendekatan dialog kehidupan dengan meletakkan keutamaan pembangunan pemikiran peserta yang terlibat. Justeru, langkah kerjasama antara pihak MAIDAM dengan badan-badan NGO yang lain seperti Malaysian Chinese Muslim Association (MACMA), Persatuan Kebajikan Islam Malaysia (PERKIM) dan Persatuan Darul Fitrah menjadi penting agar matlamat pembinaan semula hubungan antara agama dapat dicapai. Kefahaman yang menyeluruh bukan sahaja perlu mempertimbangkan bentukbentuk program yang perlu dilaksanakan tetapi juga sesuatu penyelarasan antara badanbadan dakwah tersebut (Abdul Halim, 2012). Antaranya, program dialog kehidupan yang nampak formal ialah aktiviti kerjasama 'dialog keharmonian antara agama' yang dianjurkan oleh MAIDAM, Malaysian Chinese Muslim Association (MACMA) dan Persatuan Buddha Terengganu pada 24 Disember 2011. Matlamat sebenar program ini ialah memberi kesedaran kepada komuniti Muslim dan bukan Muslim bahawa wujud ruang perkongsian dalam membicarakan soal-soal rutin kehidupan biasa seperti dalam pendidikan anak-anak, beramal nilai-nilai yang mulia, tinggal sebumbung dan sebagainya. Ini adalah kerana dalam ajaran Islam atau pun ajaran Buddha galakan mencari ilmu, mengamalkan akhlak (moral 
bagi Buddhisme) yang baik dan berbuat baik kepada ibu bapa merupakan antara amalan yang dititik beratkan. Program kerjasama yang dipupuk yang bukan sahaja berkaitan dengan pembangunan keilmuan, termasuklah juga di sini pembangunan dialog kehidupan melalui kreativiti budaya yang merangkumi bidang yang sangat luas seperti sambutan Tahun Baru Cina, pesta tang lung, tarian singa dan sebagainya. Begitu juga perkongsian aktiviti Malam Tautan Kasih yang dianjurkan oleh MAIDAM bersempena menyambut sambutan Tahun Baru Cina pada 29 Januari 2012 bertempat di Hotel Primula, Kuala Terengganu. Program yang dianjurkan ini disertai oleh 40 komuniti bukan Muslim dalam kalangan masyarakat Cina dan juga wakil-wakil dari Persatuan Kristian Terengganu. Manakala komuniti Muslim terdiri daripada masyarakat Cina Muslim dan masyarakat Melayu Muslim. Walaupun tujuan asal program ini dikhususkan kepada masyarakat Cina Muslim, pendedahan kebudayaan Cina seperti Tarian Singa, gendang Cina dan makan menggunakan 'chopstik' menjelaskan kepada masyarakat Cina bukan Muslim bahawa memeluk Islam tidak menghapuskan budaya asal mereka.

Bagi masyarakat Melayu Muslim pula, pendedahan sedemikian memberi kefahaman yang cukup signifikan bahawa memeluk Islam bukan bermakna seseorang itu menjadi Melayu. Antara program lain ialah Majlis Berbuka Puasa yang dianjurkan oleh MAIDAM negeri Terengganu bertempat di Hotel Primula, di Batu Burok, Terengganu pada 25 Julai 2012. Walaupun program ini merupakan program kebiasaan yang dilakukan oleh MAIDAM Terengganu, kelainan yang ada pada tahun ini ialah apabila dalam kalangan bukan Muslim juga dijemput hadir bagi merasai pengalaman berbuka puasa dengan rakan-rakan dan saudara mereka yang beragama Islam. Oleh kerana majoriti Saudara Baru ini terdiri daripada masyarakat Cina, sesi pengerusi dilakukan dalam dua bahasa iaitu bahasa Mandarin dan bahasa Melayu. Program ini juga dihadiri oleh wakil dari Persatuan Buddha Terengganu dan
Persatuan Kristian Terengganu. Selain daripada itu, ada dalam kalangan Cina Muslim yang membawa ahli keluarganya yang masih bukan Muslim untuk mengikuti acara berbuka puasa. Malahan penulis mendapati menu masakan yang disediakan adalah berkonsepkan ala Cina dan Melayu Muslim. Sesi pemberian zakat juga diberikan kepada Saudara Baru yang mempunyai masalah kewangan dan yang baru memeluk agama Islam. Justeru, penglibatan dialog kehidupan beragama pada peringkat ini melibatkan pelbagai lapisan masyarakat yang menganut agama Islam dan juga masyarakat bukan Muslim. Justeru juga Abdul Halim (2012) menyatakan sebagaimana berikut:

"Kita melihat program itu amat berjaya, [daripada reaksi yang ditunjukkan oleh komuniti bukan Islam, mereka teruja], sebab kalangan yang hadir dari kalangan saudara baru mereka berkomunikasi dengan bahasa mereka, kita memberi faham kepada mereka bahawa [bangsa tetap bangsa walaupun agama berlainan]".

Dialog kehidupan melalui perkongsian programprogram budaya yang dijalankan sebagaimana diterangkan di atas dapat menjelaskan salah faham bahawa Islam dan bangsa merupakan dua perkara yang berbeza. Lebih jauh lagi, pengalaman-pengalaman sedemikian dapat menjalinkan hubungan persaudaraan di samping memupuk semangat toleransi dalam beragama dan budaya. Berdasarkan kepada perbincangan di atas, dapat dinyatakan bahawa MAIDAM Terengganu mengetengahkan pelbagai bentuk perkongsian aktiviti yang mampu memupuk hubungan antara kaum dan agama. Dialog kehidupan melalui perkongsian aktiviti bertujuan memberi kefahaman, kesedaran dan menghormati kepercayaan dan amalan budaya masing-masing. Lantaran itu, tidaklah sukar seorang Muslim menyambut Tahun Baru Cina selagi mana acara yang dilakukan tidak bercanggah dengan hukum syarak Islam. Mengambil kira pengalaman hubungan antara agama dan budaya masyarakat Cina di negeri Terengganu, jalinan dialog kehidupan yang berlaku dalam bentuk turut serta dan pemerhatian 
mampu merungkaikan persoalan perbezaan agama dan budaya dalam masyarakat. Malahan kelihatan kegembiraan dan keterujaan komuniti Cina Muslim memerikan adat dan budaya asal sebagai suatu pemuliharaan peninggalan yang diwarisi sejak turun temurun.

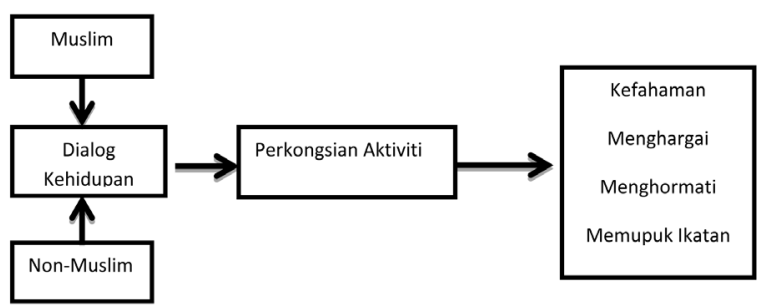

RAJAH 1: Matlamat Dialog Kehidupan Muslim dan bukan Muslim.

Berdasarkan rajah 1 di atas, dapat dinyatakan bahawa pembangunan dialog kehidupan dalam konteks pengurusan Saudara Baru adalah bertujuan memupuk hubungan antara keluarga yang berbeza agama agar saling memahami, saling menghargai dan saling menghormati perbezaan yang timbul. Ertinya, kesedaran yang menyeluruh melalui perkongsian hidup bukan sahaja mengambil kira aspek perbezaan budaya dan agama tetapi perlu ada satu pengarahan dan penyelarasan sesebuah organisasi agar kefahaman yang menyeluruh dapat membantu tercapai cita-cita pelaksanaan. Ini bermakna badan organisasi ini bertindak sebagai pusat aktiviti dan kreativiti yang menonjolkan acara kehidupan manusia yang sangat luas termasuklah kebudayaan yang bersifat semasa, pelaksanaan nilai agama Islam yang sebenar dan pemupukan semangat cintakan kepada keluarga.

\section{Metodologi}

Bagi memperolehi maklumat yang diperlukan, kajian kuantitatif dengan menggunakan kaedah pensampelan bertujuan (purposive sampling) telah dilakukan. Bagi Mokhtar (2005) kaedah pensampelan bertujuan adalah kajian yang merujuk kepada satu kumpulan yang mempunyai ciri-ciri sampel yang dikehendaki oleh penyelidik. Populasi sebenar sampel ialah seramai 92 orang dan berdasarkan jadual Krejcie \& Morgan, sekiranya populasi kajian adalah 95 maka sampel yang terbaik ialah 76 orang (Ahmad, 2009). Berdasarkan jumlah populasi seramai 92 orang dengan jumlah sampel yang diperolehi seramai 86 orang, bermakna jumlah yang diperolehi berada pada kedudukan yang tinggi iaitu 93.5\%. Borang soal selidik diedarkan bermula 15 Disember 2013 dan dikutip sepenuhnya pada 30 Januari 2014. Borang-borang soal selidik diedarkan kepada Saudara Baru Cina dengan kerjasama Majlis Agama Islam \& Adat Melayu Terengganu (MAIDAM).

Pengkaji berpendapat bahawa melalui borang soal selidik, data yang diperoleh adalah tepat dan dalam masa yang sama responden dapat memberi maklum balas yang meyakinkan. Borang soal selidik digubal dan dibina oleh pengkaji berdasarkan teori dan pandangan pakar dalam bidang 'Dialog Kehidupan' iaitu Prof. Datin Dr. Azizan Baharuddin, Timbalan Pengarah IKIM, merangkap profesor di Pusat Dialog, Universiti Malaya. Set soal selidik untuk Saudara Baru Cina digunakan untuk memperoleh respon khas terhadap pengalaman dialog kehidupan pada sebelum dan setelah memeluk agama Islam. Bagi mengukur responden dalam dialog, pengkaji menggunakan skala likert 1 hingga 5 sebagaimana yang disarankan oleh Mohd Najib (2003) iaitu 1 bagi Sangat Tidak Bersetuju (STB), 2 bagi Tidak Bersetuju (TB), 3 bagi Tidak Pasti (TP), 4 bagi Setuju (S) dan 5 bagi Sangat Setuju (SS). Data kuantitatif yang diperoleh ini diproses menggunakan perisian komputer 'Statistical package For Science' (SPSS 20.0 For Windows) untuk menganalisis data deskriptif. Analisis statistik dengan ujian min (purata) dan peratus digunakan bagi melihat persepsi Saudara Baru Cina terhadap soalansoalan yang dikemukakan.

Sebelum kajian dilakukan, penyelidik terlebih dahulu akan membuat kajian rintis dalam kalangan masyarakat Cina Muslim. Sebanyak 30 sampel diambil bagi mengetahui kebolehpercayaan item-item soalan yang dibina. Pembinaan ujian-ujian ini mengambil masa yang rencam bagi menilai kebolehpercayaan 
dan kesahannya sebelum boleh digunakan untuk tujuan penyelidikan. Hasil dapatan kajian rintis yang dilakukan pada Mac 2013, perolehan nilai alpha pada bacaan 0.8 menunjukkan dapatan ini berada dalam realibity yang tinggi. Ini bertepatan dengan indek Rowntree yang menyebut tahap Cronbach's Alpha $=0.71$ 0.90 merupakan tahap kebolehpercayaan yang kuat dan merupakan tahap kebolehpercayaan yang tinggi. Manakala mengikut Kaplan dan Saccuzzo (1982) menyatakan bahawa tahap Cronbach's Alpha $=0.71-0.80$ merupakan tahap kebolehpercayaan yang baik (Ahmad, 2009).

Bagi mendapat pengalaman yang bersifat natural dalam kalangan yang diperhatikan, pengkaji melakukan pengamatan ikut serta dengan membabitkan diri dalam aktiviti-aktiviti yang melibatkan Saudara Baru. Menurut Ahmad Sunawari (2009), dalam keadaan tertentu penyelidik berperanan sebagai pemerhati dan kadangkala bertindak sebagai peserta dengan mereka yang diperhatikan. Kaedah 'Pemerhatian Penyertaan Tanpa Kawalan' memberi peluang yang secukupnya kepada penyelidik mengkaji mereka yang terlibat dan menimbulkan rasa natural dalam kalangan yang diperhatikan.

\section{Hasil Dan Perbincangan}

\begin{tabular}{|c|c|c|c|c|}
\hline \multicolumn{2}{|c|}{ Jantina } & $\begin{array}{c}\text { Agama } \\
\text { Asal }\end{array}$ & $\begin{array}{c}\text { Faktor } \\
\text { Pemelukan }\end{array}$ & $\begin{array}{l}\text { Tempoh } \\
\text { Memeluk }\end{array}$ \\
\hline lelaki & $\begin{array}{c}44 \\
(51.2 \%)\end{array}$ & \multirow{3}{*}{$\begin{array}{c}\text { Buddha } \\
65(75.5 \%) \\
\text { Kristian } \\
10(11.6 \%) \\
\text { Confucius } \\
2 \\
(2.3 \%) \\
\\
\text { Taoisme } \\
3 \\
(3.5 \%) \\
\text { Campuran } \\
4 \\
(4.7 \%) \\
\text { Ateis } \\
2 \\
(2.3 \%)\end{array}$} & \multirow{3}{*}{$\begin{array}{c}\text { Petunjuk Dari } \\
\text { Allah } \\
31(36 \%) \\
\text { Pembacaan } \\
4(4.7 \%) \\
\text { Pergaulan } \\
27(31.3 \%) \\
\text { Dorongan } \\
\text { keluarga } \\
7(8.15) \\
\text { Perkahwinan } \\
17(19.8 \%)\end{array}$} & \multirow{3}{*}{$\begin{array}{c}1-5 \text { tahun } \\
12 \\
(14 \%) \\
\\
6-15 \text { tahun } \\
27 \\
(31.4 \%) \\
\\
\text { Lebih } 15 \\
\text { tahun } \\
47 \\
(54.7 \%)\end{array}$} \\
\hline \multirow[t]{2}{*}{ Wanita } & \multirow[t]{2}{*}{$\begin{array}{c}42 \\
(48.8 \%)\end{array}$} & & & \\
\hline & & & & \\
\hline Jumlah & 86 & & & \\
\hline
\end{tabular}

Berdasarkan kepada jadual 1 di atas, responden adalah terdiri daripada 86 masyarakat Cina yang memeluk agama Islam di negeri Terengganu iaitu 44 orang lelaki dan 42 orang perempuan. Kebanyakan responden merupakan bekas penganut agama Buddha iaitu seramai 65 orang atau $75.5 \%, 10(11.6 \%)$ adalah orang bekas penganut Kristian, 2 orang (2.3\%) merupakan bekas pengikut ajaran Confucius dan 3 orang (3.5\%) bekas penganut Taoisme, 4 orang (4.7\%) campuran dari pelbagai agama dan 2 orang $(2.3 \%)$ pula tiada agama (ateis). Ini menunjukkan bahawa majoriti masyarakat Cina di negeri ini mengamalkan ajaran yang diwarisi dari Tanah Besar Cina. Selain itu, gambaran di atas juga jelas menunjukkan bahawa dialog kehidupan selepas pemelukan agama Islam melibatkan hubungan yang terbesar berlaku antara komuniti Muslim dengan komuniti yang beragama Buddha dan Kristian. Jika dilihat tempoh pemelukan agama Islam, 12 orang (14\%) daripada responden telah memeluk agama Islam dalam lingkungan 1-5 tahun, 27 orang $(31.4 \%)$ telah memeluk agama Islam selama 6-15 tahun manakala seramai 47 orang (54.7\%) telah memeluk agama Islam lebih daripada 15 tahun. Seramai 31 orang atau $36 \%$ daripada responden menyatakan bahawa faktor yang mendorong mereka memeluk agama Islam adalah disebabkan mendapat petunjuk daripada Allah. 27 orang responden atau $31.3 \%$ menyatakan bahawa faktor pergaulan dengan rakan yang beragama Islam mendorong melakukan pemelukan agama baru. Jumlah 17 orang atau $19.8 \%$ daripada responden menyatakan bahawa mereka memeluk agama Islam kerana ingin berkahwin dengan pasangan yang beragama tersebut manakala 7 orang daripada responden menyatakan bahawa mereka melakukan pemelukan agama Islam kerana didorong oleh ahli keluarga yang telah melakukan pemelukan agama tersebut. Hasil dapatan juga mendapati hanya 4 orang daripada responden menyatakan bahawa mereka memeluk agama Islam kerana faktor pembacaan tentang agama Islam.

Dalam hubungan antara agama yang dicirikan 
oleh 'pengkayaan bersama' (mutual enrichment) perbezaan hidup orang lain, dialog kehidupan memainkan peranan penting dalam melestarikan pembangunan masyarakat agar bersama-sama merasai nikmat keamanan (Samwini, 2010). Azizan (2008) misalnya menegaskan bahawa masyarakat yang berbeza kepercayaan perlu 'memperkukuhkan jalinan perpaduan' dengan pendekatan dialog sebagai mediumnya serta berpegang kepada prinsip menerima perbezaan dalam kehidupan berbilang agama dan kaum. Pengurusan Saudara Baru berasaskan dialog kehidupan ini amat penting sebagaimana peranan yang telah dilakukan oleh MAIDAM melalui agensinya Pusat Latihan Saudara Baru Darul Hidayah yang bukan sekadar hanya pusat pengajaran agama Islam, malah badan-badan ini juga menjadi tempat komuniti Muslim baru ini berjumpa, melakukan kegiatan aktiviti dan menghubungkan silaturahim.

Berdasarkan jadual 2, hasil kajian mendapati darjah persetujuan responden terhadap item 'aktiviti yang dapat menghubungkan silaturahim' antara komuniti Saudara Baru dengan komuniti bukan Muslim berada pada tahap yang sederhana apabila skor min yang diperolehi adalah 2.79 mata. Sebanyak $24.4 \%$ yang memilih untuk bersetuju manakala $8.1 \%$ yang memilih sangat bersetuju. Bilangan yang tidak bersetuju pula merupakan jumlah yang terbanyak iaitu $38.4 \%$ manakala $11.4 \%$ memilih sangat tidak bersetuju. Soalan selanjutnya meminta responden menetapkan pendirian sejauh mana program yang dijalankan mendapat sambutan masyarakat Melayu dan komuniti bukan Muslim. Hasil kajian mendapati, hanya $16.3 \%$ yang memilih untuk bersetuju dan 9.3\% menyatakan sangat bersetuju berbanding $29.1 \%$ menyatakan tidak bersetuju dan $17.4 \%$ menyatakan sangat tidak bersetuju manakala $27.9 \%$ responden tidak dapat memberi kepastian. Pun begitu darjah persetujuan menunjukkan perihal ini masih berada pada tahap yang sederhana. Hasil dapatan yang diperolehi bagi item 'perkongsian aktiviti dengan masyarakat Muslim yang lain merupakan aktiviti yang berfaedah', skor min 4.03 menunjukkan ianya berada pada tahap yang tinggi. Ini bermakna, dialog kehidupan yang dilakukan oleh pihak majlis agama sedikit sebanyak memberi impak yang positif dalam pemupukan hubungan toleransi antara agama, budaya dan kaum di negeri Terengganu.

Secara keseluruhannya, skala yang sederhana yang diperolehi menunjukkan hasil dapatan agak berbeza dengan kajian yang dilakukan oleh Azmi Suratman dan Azrinah (2010) yang mendapati faktor penglibatan komuniti yang berbeza agama dalam dialog antara agama di IPT berada pada tahap yang tinggi. Hasil dapatan kajian yang sederhana memperlihatkan badanbadan dakwah dan NGO Saudara Baru di negeri Terengganu berhadapan sedikit permasalahan dalam merealisasikan dialog kehidupan di negeri Terengganu. Biarpun begitu, dapatan ini serba sedikit menyokong kajian yang dilakukan oleh Mohd Zaid Mohd Zain (2004) di Negeri Sembilan yang mendapati peranan PERKIM agak memberangsangkan menguruskan kemelut yang berlaku dalam kalangan Saudara Baru.

Sememangnya isu yang paling kontroversial dalam konteks hubungan Saudara Baru dengan keluarga bukan Muslim ialah pelaksanaan nilai dan amalan agama Islam. Bagi komuniti Cina,

JADUAL 2: Peranan Majlis Agama Dalam Dialog Kehidupan

\begin{tabular}{|c|c|c|c|c|c|c|c|}
\hline Bil & Soalan & STS & TS & $\mathrm{TP}$ & $\mathrm{S}$ & SS & Min \\
\hline 1 & $\begin{array}{l}\text { Pihak Majlis Agama menjalankan banyak } \\
\text { aktiviti yang dapat menghubungkan } \\
\text { silaturahim antara masyarakat Cina Muslim } \\
\text { dan masyarakat Cina bukan Muslim. }\end{array}$ & $\begin{array}{c}10 \\
11.6 \%\end{array}$ & $\begin{array}{c}33 \\
38.4 \%\end{array}$ & $\begin{array}{c}15 \\
17.4 \%\end{array}$ & $\begin{array}{c}21 \\
24.4 \%\end{array}$ & $8.1 \%$ & 2.79 \\
\hline 2 & $\begin{array}{l}\text { Program yang dianjurkan oleh Majlis } \\
\text { Agama tersebut mendapat sambutan dalam } \\
\text { kalangan masyarakat Melayu Muslim dan } \\
\text { bukan Muslim }\end{array}$ & $\begin{array}{c}15 \\
17.4 \%\end{array}$ & $\begin{array}{c}25 \\
29.1 \%\end{array}$ & $\begin{array}{c}24 \\
27.9 \%\end{array}$ & $\begin{array}{c}14 \\
16.3 \%\end{array}$ & $\begin{array}{c}8 \\
9.3 \%\end{array}$ & 2.71 \\
\hline 3 & $\begin{array}{l}\text { Saya merasakan perkongsian aktiviti } \\
\text { dengan masyarakat Muslim yang lain } \\
\text { merupakan aktiviti yang berfaedah }\end{array}$ & $2.3 \%$ & $\begin{array}{c}5 \\
5.8 \%\end{array}$ & $\begin{array}{c}8 \\
9.3 \%\end{array}$ & $\begin{array}{c}44 \\
51.2 \%\end{array}$ & $\begin{array}{c}27 \\
31.4 \%\end{array}$ & 4.03 \\
\hline
\end{tabular}


agama dan budaya merupakan sesuatu yang amat rapat dengan kehidupan dan merupakan satu warisan kolektif yang menentukan cara hidup mereka (Norhana, 2012). Oleh kerana sifatnya demikian, sentimen terhadap kebudayaan dan kepercayaan asal apabila bertembung dengan kebudayaan yang lain ternyata amat kuat. Untuk itu, Abdul Halim (2012) menyatakan bahawa ahli keluarga dan komuniti asal yang bukan Muslim perlu diberi kesedaran agar dua pandangan yang berkontradiksi dapat diharmonikan. Bagi komuniti Saudara Baru, dampak konflik perlu ditangani dari dua pihak iaitu hubungan dengan keluarga asal yang berbeza agama dan hubungan dengan Muslim asal yang berbeza budaya. Proses membetulkan stigma negatif melalui pendekatan dialog kehidupan sebagaimana yang disarankan oleh Majlis Agama menjadikan setiap peserta yang terlibat memainkan peranan untuk bersamasama menyuburkan ikatan persaudaraan. Justeru itu, pihak MAIDAM merasa optimis bahawa pengurusan Saudara Baru melalui pendekatan dialog kehidupan akan membuahkan hasil yang baik asalkan ia dilakukan dengan niat yang jujur dan tidak melanggar syariat agama. Dengan itu pihak Majlis juga menyarankan supaya Saudara Baru lebih memperkongsikan nilai-nilai baik agama bagi mempertingkatkan kefahaman ahli keluarga bukan Muslim terhadap agama Islam. Jadi dalam pengurusan dialog kehidupan Saudara Baru terangkum saranan perkongsian hidup seperti amalan kunjungan ziarah, pelaksanaan amalan Islam di rumah keluarga bukan Muslim, perkongsian budayabudaya asal dan sebagainya. Tujuannya ialah bagaimana konsep dialog kehidupan ini dapat dijadikan sebagai satu tunggak pemupukan hubungan antara agama. Lebih-lebih lagi kerana nilai kekeluargaan dan kebudayaan asal dilihat sebagai benteng mempertahankan identiti dan maruah bangsa.

Matlamat MAIDAM dalam pengurusan Saudara Baru tidak lain daripada hendak menjaga kebajikan yang menyeluruh. Termasuk disini agenda pemupukan hubungan antara agama yang dilakukan dengan pelbagai pendekatan. Oleh itu, apa yang disarankan oleh pihak MAIDAM ialah dengan melibatkan Saudara Baru dan ahli keluarga bukan Muslim dengan sikap yang rasional, jujur dan bertoleransi. Dalam kata lain, dialog kehidupan Saudara Baru dan komuniti bukan Muslim merupakan satu usaha untuk membetulkan salahfaham nilai-nilai agama Islam yang diamalkan oleh seorang Muslim. Malahan, pengalaman perkongsian aktiviti memperlihatkan bagaimana peserta bersoal jawab (berdialog) intra etnik bagi memahami fenomena yang berlaku dalam agama yang berbeza.

Dalam perihal ini, jadual 3 menunjukkan $61.6 \%$ daripada responden memilih untuk bersetuju dan $16.3 \%$ menyatakan sangat bersetuju 'menjelaskan amalan dan ajaran agama Islam kepada rakan atau keluarga yang bukan Muslim' sewaktu dialog berlangsung. Walau bagaimana pun jumlah yang tidak bersetuju sebanyak $15.1 \%$ dan sangat tidak bersetuju pula 7\%. Skor min 3.87 mata menunjukkan darjah persetujuan berada pada skala yang tinggi. Didapati kumpulan yang memeluk agama Islam lebih dari 15 tahun mempunyai

JADUAL 3: Majlis Agama melalui Peranan Saudara Baru Dalam Pengurusan Dialog Kehidupan

\begin{tabular}{|c|c|c|c|c|c|c|c|}
\hline Bil & Soalan & STS & TS & TP & S & SS & Min \\
\hline 4 & $\begin{array}{l}\text { Saya menerangkan amalan dan pengajaran } \\
\text { agama Islam kepada rakan/keluarga yang } \\
\text { bukan Muslim. }\end{array}$ & $\begin{array}{c}6 \\
7 \%\end{array}$ & $13 \%$ & $\begin{array}{c}0 \\
0 \%\end{array}$ & $\begin{array}{l}53 \\
61.6 \%\end{array}$ & $16.3 \%$ & 3.87 \\
\hline 5 & $\begin{array}{l}\text { Keluarga/rakan saya yang bukan Muslim } \\
\text { pernah bertanya tentang amalan-amalan } \\
\text { yang dilakukan oleh saya. }\end{array}$ & $2.3 \%$ & $9.3 \%$ & $5.8 \%$ & $\begin{array}{c}62 \\
72.1 \%\end{array}$ & $10.5 \%$ & 3.79 \\
\hline 6 & $\begin{array}{l}\text { Saya pernah melaksanakan ibadat Islam di } \\
\text { rumah keluarga asal yang bukan Muslim }\end{array}$ & $4 . \stackrel{4}{7} \%$ & $\begin{array}{c}18 \\
20.9 \%\end{array}$ & $16 \%$ & $\begin{array}{c}40 \\
46.5 \%\end{array}$ & $110 \%$ & 3.40 \\
\hline 7 & $\begin{array}{l}\text { Perkongsian aktiviti yang mengandungi } \\
\text { unsur agama dengan keluarga asal mampu } \\
\text { membina perdamaian. }\end{array}$ & $2.3 \%$ & $1.2 \%$ & $\begin{array}{c}6 \\
7 \%\end{array}$ & $\begin{array}{l}59 \\
68.6 \%\end{array}$ & $20.9 \%$ & 4.05 \\
\hline
\end{tabular}


kecenderungan bersoal jawab perihal agama Islam lebih tinggi daripada kumpulan yang memeluk agama Islam pada tempoh 1-5 tahun dan 6-15 tahun. Ini dijelaskan sebagaimana dalam jadual 3.1 seperti di bawah:

Report
Dialog_slps_Cina 5
\begin{tabular}{|c|c|c|c|}
\hline Jangka_masa & Mean & N & Std. Deviation \\
\hline $1-5$ & 3.6667 & 12 & .88763 \\
$6-15$ & 3.6667 & 27 & .83205 \\
lebih 15 & 4.0426 & 47 & .65798 \\
Total & 3.8721 & 86 & .76384 \\
& & & \\
\hline
\end{tabular}

JADUAL 3.1: Respons Bersoal Jawab Mengikut Tempoh Pemelukan Agama Islam

Bagi soalan yang seterusnya, hasil dapatan menunjukkan kebanyakan rakan dan ahli keluarga bukan Muslim memberi respons terhadap penglibatan dalam dialog kehidupan dengan bertanya amalan-amalan yang dilakukan oleh responden. Sebanyak $72.1 \%$ memilih untuk bersetuju dan $10.5 \%$ menyatakan sangat bersetuju terhadap soalan yang diberikan. Namun begitu, skor min 3.79 masih menunjukkan respons rakan dan ahli keluarga dalam penglibatan dialog kehidupan adalah sederhana. Walaupun ahli keluarga bertindak dengan bertanya amalan-amalan yang dilakukan oleh responden, didapati hanya $68.1 \%$ (S dan SS) pernah melaksanakan ibadat yang dianjurkan oleh agama Islam di rumah keluarga bukan Muslim. Jumlah golongan yang tidak bersetuju pula sebanyak $20.9 \%$ manakala $16.3 \%$ daripada responden tidak dapat memberi keputusan. Justeru, skor min 3.40 menunjukkan darjah persetujuan masih berada pada tahap yang sederhana. Soalan yang berikutnya, hasil dapatan menunjukkan bahawa hanya $68.6 \%$ daripada responden bersetuju dan $20.9 \%$ yang sangat bersetuju menyatakan perkongsian aktiviti yang mengandungi unsur keagamaan mampu membina perdamaian. Skor min 4.05 mata menunjukkan darjah persetujuan berada pada tahap yang tinggi

Sememangnya peranan komuniti Cina Muslim dalam memberi kefahaman dan menghilangkan kesamaran ahli keluarga melalui perkongsian budaya adalah sangat signifikan. Dalam kata lain, komuniti Saudara Baru mampu melihat secara 'inside-out' potensi dalaman untuk berinteraksi dengan masyarakat sendiri dan menjelaskan sistem nilai berdasarkan kreativiti mengikut acuan sendiri tanpa melanggar normanorma agama. Manifestasinya, terjelmalah segala kebenaran, menghilangkan prasangka dan membina ikatan yang dapat meleraikan persengketaan selama ini.

Kebudayaan dipernyatakan sebagai satu cara hidup yang dilahirkan melalui proses penghayatan, nilai-nilai yang tinggi, sikap dan pemikiran yang semestinya mempertingkatkan martabat sesebuah bangsa (Shamsul 2011). Ini bermakna persoalan kebudayaan merupakan isu pokok bagi setiap bangsa bagi mempertahankan kemahuan dan keyakinan masing-masing. Di sebaliknya, hubungan antara keluarga tidak dapat bersatu sekiranya pihak MAIDAM tidak bertindak dan mempelopori pemupukan perpaduan antara keluarga. Justeru, dalam konteks hubungan intra etnik pasca konversi, pengalaman dialog kehidupan Saudara Baru juga memaparkan perkongsian budaya dan adat resam yang diwarisi. Dengan demikian, responden ditanya soalan-soalan yang berkaitan dengan penglibatan dalam budaya dan adat resam yang asal. Sebagai contoh, perkongsian budaya asal ini boleh diperhatikan dalam sambutan Tahun Baru Cina bersama keluarga bukan Muslim. Berdasarkan jadual 4, hasil kajian menunjukkan $46.5 \%$ responden menyatakan bersetuju dan $25.6 \%$ memilih sangat bersetuju menyambut perayaan tersebut bersama keluarga bukan Muslim. Pun begitu, skor min 3.79 mata menunjukkan perkongsian ini masih belum mencapai tahap yang tinggi. Begitu juga dalam item yang berkaitan "meraikan tradisi makan bersama sempena Tahun Baru Cina dengan keluarga bukan Muslim", didapati skor min 2.84 menunjukkan ianya berada dalam tahap yang sederhana. Kebanyakan responden memilih untuk tidak bersetuju iaitu sebanyak $41.9 \%$ dan sangat tidak bersetuju sebanyak $11.6 \%$ berbanding yang bersetuju hanya 
JADUAL 4: Meraikan Bersama-sama Kebudayaan Asal

\begin{tabular}{|c|c|c|c|c|c|c|c|}
\hline Bil & Soalan & STS & TS & $\mathrm{TP}$ & $\mathrm{S}$ & SS & Min \\
\hline 8 & $\begin{array}{l}\text { Saya masih menyambut Tahun Baru Cina } \\
\text { bersama-sama keluarga atau masyarakat } \\
\text { Cina bukan Muslim. }\end{array}$ & $2.3 \%$ & $\begin{array}{c}12 \\
14 \%\end{array}$ & $\begin{array}{c}10 \\
11.6 \%\end{array}$ & $\begin{array}{c}40 \\
46.5 \%\end{array}$ & $\begin{array}{c}22 \\
25.6 \%\end{array}$ & 3.79 \\
\hline 9 & $\begin{array}{l}\text { Saya masih meraikan tradisi makan } \\
\text { bersama sempena Tahun baru Cina dengan } \\
\text { keluarga bukan Muslim. }\end{array}$ & $\begin{array}{c}10 \\
11.6 \%\end{array}$ & $\begin{array}{c}36 \\
41.9 \%\end{array}$ & $\begin{array}{c}8 \\
9.3 \%\end{array}$ & $\begin{array}{c}22 \\
25.6 \%\end{array}$ & $\begin{array}{c}10 \\
11.6 \%\end{array}$ & 2.84 \\
\hline 10 & $\begin{array}{l}\text { Saya turut meraikan pesta tanglung dan } \\
\text { tarian singa semasa sambutan Tahun Baru } \\
\text { Cina. }\end{array}$ & $\begin{array}{c}3 \\
3.5 \%\end{array}$ & $\begin{array}{c}20 \\
23.3 \%\end{array}$ & $\begin{array}{c}14 \\
16.3 \%\end{array}$ & $\begin{array}{c}38 \\
44.2 \%\end{array}$ & $\begin{array}{c}11 \\
12.8 \%\end{array}$ & 3.40 \\
\hline 11 & $\begin{array}{l}\text { Saya turut menjemput jiran, rakan bukan } \\
\text { Muslim bagi meraikan Sambutan Tahun } \\
\text { Baru Cina. }\end{array}$ & $10.5 \%$ & $\begin{array}{c}31 \\
36 \%\end{array}$ & $\begin{array}{c}11 \\
12.8 \%\end{array}$ & $\begin{array}{c}28 \\
32.6 \%\end{array}$ & $\begin{array}{c}7 \\
8.1 \%\end{array}$ & 2.92 \\
\hline 12 & $\begin{array}{l}\text { Saya menghadiri majlis perkahwinan yang } \\
\text { dianjurkan oleh saudara mara saya yang } \\
\text { bukan Muslim. }\end{array}$ & $\begin{array}{c}4 \\
4.7 \%\end{array}$ & $\begin{array}{c}11 \\
12.8 \%\end{array}$ & $\begin{array}{c}18 \\
20.9 \%\end{array}$ & $\begin{array}{c}41 \\
47.7 \%\end{array}$ & $\begin{array}{l}12 \\
14 \%\end{array}$ & 3.53 \\
\hline
\end{tabular}

$25.6 \%$ dan sangat bersetuju sebanyak $11.6 \%$. Ini menunjukkan responden begitu berhatihati dalam menjalinkan dialog kehidupan agar aktiviti yang dilakukan tidak bersalahan dengan syariat agama Islam.

Selain daripada itu, pengalaman dialog kehidupan dalam perkongsian budaya asal boleh diperhatikan juga ketika melibatkan diri dalam pesta tanglung dan tarian singa dengan $44.2 \%$ memilih untuk bersetuju dan $12.8 \%$ menyatakan sangat bersetuju. Biarpun skor min 3.40 menunjukkan penglibatan dalam aktiviti ini berada pada tahap yang sederhana, didapati $23.3 \%$ yang tidak bersetuju dengan soalan ini manakala $16.3 \%$ tidak dapat memberi kepastian. Menjadi Saudara Baru, bukanlah menghalang sebahagian komuniti Cina pasca konversi meraikan sambutan Tahun Baru Cina dengan rakan bukan Muslim. Justeru, hasil kajian mendapati 32.6\% menyatakan bersetuju dan $8.1 \%$ memilih sangat bersetuju berbanding $36.5 \%$ menyatakan tidak bersetuju manakala $10.5 \%$ berpendirian sangat tidak bersetuju. Pun begitu, perolehan skor min 2.92 mata menunjukkan bahawa perihal ini masih berada pada tahap yang sederhana. Begitu juga dalam perkongsian kegembiraan dengan meraikan majlis perkahwinan yang dianjurkan oleh keluarga asal berada pada skala yang sederhana apabila skor min hanya mencatatkan 3.53 sahaja. Sebanyak 47.7\% menyatakan bersetuju manakala $14 \% \%$ memilih sangat bersetuju pada soalan yang diberikan.
RAJAH 2: Implikasi Pengurusan Berteraskan Dialog Kehidupan DIALOG KEHIDUPAN

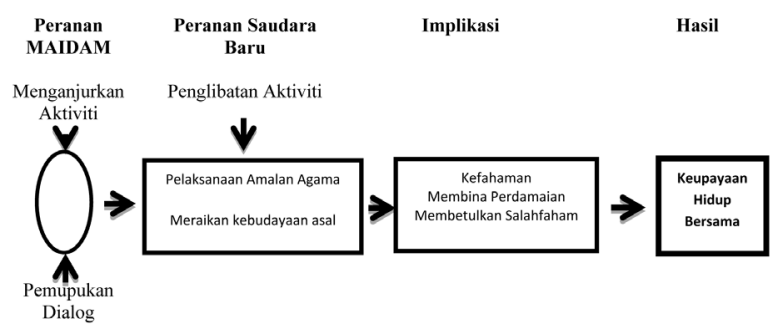

Berdasarkan kepada rajah 2 di atas, dapat dinyatakan bahawa peranan Saudara Baru dalam pentas dialog kehidupan begitu luas, selain menjelaskan tentang praktis agama Islam melalui amalan-amalan keagamaan seperti solat, berpuasa, menutup aurat dan sebagainya, komuniti Cina Muslim juga berperanan memecahkan persepsi negatif keluarga bukan Muslim melalui penglibatan bersama dalam budaya asal. Sememangnya pengalaman pembabitan komuniti Cina Muslim dalam aktiviti seperti tarian naga, sambutan Tahun Baru Cina, malam Tautan Kasih yang menggabungkan masyarakat Cina Bukan Muslim, Melayu Muslim dan Cina Muslim dapat memupuk memberi kesedaran yang bermakna kepada banyak pihak. Ternyata, komuniti Cina begitu teruja memanifestasikan kegembiraan yang dijelmakan melalui perkongsian kegiatan budaya asal mereka. Pengurusan pihak MAIDAM yang menjadikan dialog kehidupan sebagai satu pendekatan semestinya sedikit sebanyak memberi implikasi terhadap pembinaan hubungan antara kaum dan agama di negeri ini. Apa yang nyata, tidak 
ada negara yang ingin melahirkan masyarakat yang berpecah belah, konflik dan mempunyai norma hidup yang bercanggah. Biarpun wujud ketidakseragaman, satu formula yang bersepadu amat perlu bagi membina bangsa Malaysia yang bersatu. Justeru, sewajar pengurusan yang melibat kaum dan agama yang pelbagai perlu dikembangkan dalam semua agensiagensi kerajaan agar semua pihak berpeluang menjelaskan nilai dan norma hidup masingmasing tanpa sebarang sikap prejudis.

\section{Kesimpulan}

Kesedaran terhadap peri pentingnya dialog kehidupan akan membantu tercapainya hasrat pelaksanaan pemupukan hubungan antara agama dan kaum di Malaysia dalam masa yang sewajarnya. Justeru, sewajarnya perbezaan dalam beragama dan berbudaya tidak diretakkan oleh pertentangan yang timbul. Dari segi konsep dan pelaksanaan, MAIDAM mengambil insiatif bahawa pendekatan dialog kehidupan merupakan sebahagian daripada pengurusan Saudara Baru yang sangat penting. Peranan MAIDAM ini sedikit sebanyak mampu menanamkan persefahaman, membina perdamaian dan membetulkan salahfaham dalam merealisasikan aktiviti kehidupan seharian. Perihal ini dibuktikan apabila majoriti komuniti Saudara Baru melihat dialog kehidupan melalui perkongsian aktiviti yang berlaku dalam agama Islam mampu membetulkan salah faham dalam kalangan ahli kekuarga bukan Muslim. Dari sudut yang lain, pihak MAIDAM melihat pemuafakatan bersama boleh dilaksanakan melalui implimentasi norma dan nilai yang tidak bercanggah yang sedia ada dalam kebudayaan asal. Untuk itu, dialog kehidupan perkongsian aktiviti asal Saudara Baru merupakan aktiviti pokok yang sewajarnya diurus dengan berhikmah, sabar dan tanggungjawab bersama. Tujuannya ialah mewujudkan perdamaian yang hakiki dengan keluarga yang tercinta.

\section{Rujukan}

Abdul Halim Lim Abdul Rahman. 2012. Mohd Najib Abdul Ghafar. 2003. Reka Bentuk
Pengetua Kompleks Darul Hidayah. Dalam temu bual dengan penulis pada 26 Mac 2006(9.00 pagi) di pejabat agama MAIDAM, Bukit Besar, Kuala Terengganu.

Ahmad Sunawari Long. 2009. Pengenalan Penyelidikan Pengajian Islam. Bangi: UKM.

Azizan Baharuddin. 2008. Peranan Dialog Peradaban Di Dalam Wacana Tamadun Malaysia, Jurnal Peradaban-Jurnal Rasmi Pusat Dialog Peradaban, Universiti Malaya, Jilid 1: 1-20.

Azmi Shah Suratman \& Azrinah Abdul Rahah. 2010. Persepsi Pelajar Terhadap Dialog Antara Agama: Kajian Dalam Kalangan Pelajar Tahun 4, Fakulti Pendidikan. Skudai: Universiti Teknologi Malaysia.

Bilangan Pemelukan Saudara Baru Negeri Terengganu. (2012). Bahagian Dakwah, Pejabat Agama Negeri Terengganu.

Dawi, A. H. 2010. Kepentingan Identiti dan Perjuangan Etnik dalam Masyarakat Malaysia. Makalah Persidangan Antarabangsa Minoriti dan Majoriti: Bahasa, Budaya dan Identiti, Kuching, Sarawak, (23-24 November 2010): 1-12.

Fitzgerald, M.L. 2005. The Catholic Church and Interreligious Dialogue. laman sesawang Buletin 75, October 2005. Dicapai 23 November 2011. http://76.227.210.78/a.php?id=723.

Forward, M. 2001. Inter-religious dialogue: a short introduction. England: Oneworld.

Ibnu Manzur. 2001. Lisān al-'Arab lil iman al-alamat Abi al-Fadli Jamal al-Din Muhammad bin Makram. Beirut: Dar al-Sadir.

Mohamed Azam Mohamed Adil. 2006. “Undang-Undang Atau Bidang Kuasa?",Utusan Malaysia, 10 Dis 2006. 
Tinjauan Soal Selidik Penyelidikan. Skudai: Universiti Teknologi Malaysia.

Mohd Zaid Mohd Zain. 2004. Kesan Pengajaran Dan Pendidikan Agama Di Kalangan Saudara Baru: Kajian di PERKIM Negeri Sembilan. Disertasi Sarjana Universiti Kebangsaan Malaysia.

Mokhtar Ismail. 2011. Kaedah Penyelidikan Kuantitatif dalam Pendidikan. Kuala Lumpur: Dewan Bahasa \& Pustaka.

Norhana Ng Abdullah. 2012. Pengerusi Persatuan Darul Fitrah Negeri Terengganu, merangkap Pengerusi MACMA Terengganu. Dalam temu bual dengan penulis pada 12 . Mac 2012 (11.00 pagi) di Pejabat Darul Fitrah di Bukit Besar, Kuala Terengganu.

Rahimin Affandi Abd. Rahim, Mohd Anuar Ramli, Paizah Ismail dan Nor Hayati Mohd Dahlan. 2011. Dialog Antara Agama: Realiti dan Prospek Di Malaysia, Kajian Malaysia, 29:2: 91-110.
Samwini, N.I. 2010. The Need for and Importance of Dialogue of Life in Community Building: The Case of Selected West African Nations. A forum for academic, social, and timely issues affecting religious communities around the world. Dicapai 10 November 2011, www.irdialogue.org/submissions.

Shamsul Amri Baharuddin. 2011. Hubungan Etnik. Shah Alam: UPENA UiTM.

Sintang, S., and K. Hambali. 2010. Dialog kehidupan di Sabah: Analisis pengalaman saudara baru. (2010): 1-29. Dalam Seminar Serantau Islam dan Kesejahteraan Sejagat, Februari 2010, Universiti Islam Sultan Sharif Ali Brunei Darussalam. 24-25.

Tyagananda, S. 2011. Doing Dialogue Interreligiously. Dialog: A Journal of Theology Volume 50, Number 3(2011): 227- 30.

Volker, K. 2004. Who, With Whom, About What? Exploring the Landscape of Inter Religious Dialogue. Exchange 33.1: 73-92. 
